\title{
Collective Opinion Formation for Public Decision Making in Local Governments
}

\author{
Ye Tian \\ College of Information Sciences and Technology \\ University Park, PA 16802, USA \\ yxt157@ist.psu.edu
}

\author{
Guoray Cai \\ College of Information Sciences and Technology \\ University Park, PA 16802, USA \\ cai@ist.psu.edu
}

\begin{abstract}
Democratic decision making on public issues requires that a collective form of public opinion be constructed in order to be legitimate. However, elicitation of collective public opinion has been challenging due to conceptual and methodological difficulties as well as practical constraints. This paper revisits existing methods of civic engagement through the lens of structured public decision making, and reveals the disconnects between methods of public opinion and the need for establishing public value and solid decision analysis in democratic decision making. This explains why the current online deliberation systems fail to support formation of decisionrelevant public opinions. Based on such understanding, we propose Community Opinion Elicitation (COPE) as a solution to public engagement in local government decision making. COPE envisions a three-phase process where opinions from the general public are elicited (Phase III) only after public values and solid decision analysis have been established (Phases I and II). In practice, COPE is implemented by extending traditional online deliberation with two smallgroup deliberations that address public value identification and decision analysis. This process has been deployed by State College municipal government as a formal method to engage the public. We report our findings from such field exercises and their implications to scaling up online deliberation for public decision making.
\end{abstract}

\section{CCS Concepts}

-Applied computing $\rightarrow$ E-government; •Human-centered computing $\rightarrow$ Computer supported cooperative work;

\section{Keywords}

Public decision making, public value, collective public opinion

\section{INTRODUCTION}

Permission to make digital or hard copies of all or part of this work for personal or classroom use is granted without fee provided that copies are not made or distributed for profit or commercial advantage and that copies bear this notice and the full citation on the first page. Copyrights for components of this work owned by others than ACM must be honored. Abstracting with credit is permitted. To copy otherwise, or republish, to post on servers or to redistribute to lists, requires prior specific permission and/or a fee. Request permissions from permissions@ acm.org.

dg.o '16, June 08-10, 2016, Shanghai, China

(c) 2016 ACM. ISBN 978-1-4503-4339-8/16/06 . \$ $\$ 15.00$

DOI: http://dx.doi.org/10.1145/2912160.2912194
A great challenge of modern society is to make decisions on hard choices in a democratic fashion, leveraging collective knowledge and wisdom of the public, experts, and authorities [50, 12]. Such democratic decision making must incorporate the opinions of all those who have a stake on a public issue. To be valid input to decision making, public opinion should be informed by the collective opinions of the public as a whole. Ideally, collective opinions are organic synthesis of individual opinions in a form that is equivalent to having one "mind" for the whole community [4]. Collective opinions consist of ideas highly connected, mutually informed, fully justified and broadly recognized. In reality, however, this collective form of public opinion is rarely achieved, causing huge public opinion deficit.

The reason for public opinion deficits is many-sided. Deliberative democracy theorists believe that collective public opinion can only emerge from deliberation and dialogues where all facts, values, and positions are fully considered $[13,29]$. However, this method of public opinion development does not scale well for communities with hundreds or thousands of individuals. With the emergence of online deliberation technologies, mass participation of community conversation is now reality $[54,9,52]$. The design of online deliberation systems has been focused on achieving the properties of idealized public sphere [19]. While they are good at collecting a breadth of observations, personal stories, experiences, judgment, and perspectives, these accumulations of individual ideas do not automatically become collective judgments [16, 3, 23]. Although citizens' opinions have certain degree of exposure in online community forums, expressions there are typically scattered individual ideas that may be incoherent, biased, partial, and isolated. There exists a huge gap between the collected knowledge state (what you and I think) and the collective knowledge state (what we think). Transforming distributed/local knowledge into community intelligence [56] is a complex, collaborative, and learning process, which requires careful management, facilitation, and incubation.

Motivated by the goal of enabling the formation of collective opinion in public decision making through massive online deliberation, this paper presents a close inspection on the notion of collective public opinion guided by the theories of deliberative democracy, public decision making, and opinion formation. By imposing the requirement of collectivity, we identify three major challenges of constructing legitimate public opinion: (1) the recognition and identification of $p u b$ lic values; (2) the information barrier for forming reasoned and stable opinion; and (3) scaling up mass participation 
and deliberation. Unfortunately, existing methods of collecting public opinion fail to address the three challenges as a whole, causing opinion outcomes half-baked on a shaky information ground.

In this paper, we propose a method to address all three challenges in the context of public decision making in local governments. Our method, Community Opinion Elicitation (COPE), envisions a three-phase process to achieve the complex goal of collective opinion formation. After a brief review of public opinion development methods (Section 2), we identify three challenges of collective public opinion formation in the context of public decision making (Section 3). To address them, we argue that public opinion formation process should be closely matched to the public decision-making process, where public value identification and decision analysis are performed before mass public opinion are invited. We describe our general approach (Section 4) as well as our implementation of the COPE method (Section 5). Finally, we report our implementation of the COPE method in our field experiments with State College Borough government, and discuss our findings and implications to online deliberation technologies (Section 6).

\section{PUBLIC OPINION IN DEMOCRATIC DE- CISION MAKING}

Democratic governance calls for public input to inform decision making on public issues, namely issues that have the potential to impact all individuals in a community. Public opinion consists of the public's position and judgments on a pending decision and reflects the public's interests and preferences [2]. The legitimacy of any decisions to act on a public issue is based on the fact that they are made to protect the public's interests [34]. Public opinion must enter the purview of whoever have to act (decision makers), such as public administrator and policy maker. Otherwise, public opinion is impotent and meaningless because of not affecting the action or operation of the society [35].

For public opinion to be legitimate input to the decisionmaking authorities, they are expected to be collective and well-informed [38]. Collectivity addresses that public opinion should represents "what we think" instead of "what you and I think". Informedness entails that the public opinion should be supported by reasoned arguments that exploit knowledge about the issue, especially on the consequences of the identified solutions. In this paper, we refer to this knowledge as decision analysis knowledge. However, how to achieve collective and informed public opinion remains an open challenge.

Early practices of measuring public opinion mostly consisted of survey, polling, and voting. These methods have their origin in liberal democracy $[1,55,22]$ which believes that the polity is nothing but a collection of individuals attempting to maximize their own interests and utilities. The harmonization of these conflicting interests was best achieved not through rule by majority. Public opinion is equated to the aggregation of individual opinions. Opinion polls and popular referendums, despite their democratic aims, are prone to amplify defective opinions formed without any meaningful public debate [37]. The result is a citizenry converted into a body that consumes political views disseminated by elites through the mass media, rather than an autonomous, deliberating body that discovers its own views.
Liberal democracy view of public opinion suffers from the critics that ordinary citizens are emotional and irrational, and unable to discriminate intelligently among various policies. Mass opinions based on surveys and polling can be disastrously unstable, particularly in times of cultural and political stress. At times, elite democracy dominates when citizens form their opinions almost exclusively based on elite information sources, such as government officials, journalists, domain experts and policy specialists. The access to information varies significantly between those who are ignorant about their community and those who keep themselves informed [8]. The lack of information results in an insufficient justification of judgments. In the case where people are minimally informed on the issue, their opinions can be incomplete, unsure, superficial, inconsistent, and non-responsible [27, 55]. Their response to opinion surveys manifests strong randomness: "the opinion statements vacillate randomly across repeated interviews of the same people ... Entirely trivial changes in questionnaire construction, such as switching the order in which questions are asked or response options are listed, can easily produce 5 to 10 percentage point shifts in aggregate opinion" [57, p. 28]. Although different survey techniques are developed to address the randomness [6, 38], the lack of information base and ignorance of public values render the opinions inconsistent and unstable.

As a response to these critics, recent development of public opinion methods emphasize more structured form of communication and deliberation, inspired by the participatory democratic theory in general and "deliberative democracy" theories in particular [10]. Communicative approaches emphasize the importance of using reasoned arguments to convince each other in order to gain greater collectivity. During public deliberation, people listen attentively and respond actively as they voice individual opinions $[49,5]$. As individual opinions get associated with each other, real consensus as well as disagreements are discovered. Opinions with convincing support gain more collective status.

A large array of participatory methods for public decision making have been explored both in theory and in practice [44, 43, 41]. These include stakeholder workshops, citizen juries, consensus conferences, deliberative opinion polls, negotiated rule-making, task forces, and town meetings.

1. Stakeholder workshop convenes small group of participants representing various interest groups to examine an issue and discuss it with politicians and administrators. Such a group may be used to monitor the progress of the project and inform the community about new information concerning the project's implementation.

2. Town meetings are mechanisms of direct democracy at the local, municipal, and district levels. Open discussion and questioning of authorities may end with voting, which is used to aggregate citizens' opinions, leading to decisions.

3. Citizen jury draws on the symbolism and practice of a jury in a court. The jury is made up of people usually selected at random from the target population. The jurors question experts who provide different perspectives on the topic, and produce a summary of their conclusions. This may be supervised by an advisory 
panel composed of people with relevant knowledge and interest in the outcome but who take no direct part in the jury deliberations. Members of this group subsequently decide whether to respond to, or act on, elements of the report.

4. Deliberative opinion poll is a variant of opinion polls incorporating deliberative democracy principles [11]. A deliberative poll samples public opinion after engaging citizens in deliberative conversations, through which they acquire information from each other and collaboratively develop a better understanding of the issue at hand. A comparison of opinions before and after the deliberative poll suggests that after exposure to discussions and information, citizens become much more certain and confident with their opinions, and are much more capable of justifying their choices [42, $46]$.

Common to these methods is the belief that public opinion formation must be based on an awareness and consideration of different perspectives and arguments from different stakeholders, and they represent different proposals for achieving collectivity and stability through a direct and deliberative communication among individuals $[2,18,8]$. Public opinion formation through deliberative dialogues makes two major differences. First, deliberation makes it much easier for individuals to discover alternative values from different stakeholder groups [27]. In deliberation, participants actively make sense of the values behind different expressed opinions or statements of preference. Furthermore, deliberative communication facilitates a collaboratively constructed information base on the issue at hand $[5,39]$. This information base achieves better quality in both comprehensiveness and veracity. Information acquired from authoritative channels is supplemented by learning each other's experience and stories. On the other hand, unverifiable or false information can be eliminated through conversation, and the information base is purified and consolidated.

\section{CHALLENGES OF COLLECTIVE OPIN- ION IN LOCAL GOVERNMENT}

Existing deliberative methods for fostering public opinion are designed to involve the public only in the evaluation stage of a policy proposal. Although these methods work well in national and state level issues, local communities have repeatedly expressed dissatisfaction of such late opinion gathering on a very short notice [37]. Local communities are motivated to get involved in the early phases of decision making, including framing of issues, public value recognition, agenda settings, and exploration of alternative solutions. Such needs render existing methods inadequate for local contexts. Price and Neijens [38] have argued that public opinion formation process should be inextricably tied to the democratic decision making. However, the process is too large and complex for one exercise to handle, as we explain below.

\subsection{Public decision making and the roles of public input}

Decision making in a democratic society is a complex, over-time process involving several phases and implicating multiple groups of actors: political leaders, interest groups, journalistic community, the attentive public, and much larger mass audiences. Rationalist view of public decision making generally conceptualizes the process as having five recognizable stages [40, 14, 38, 24]: (1) identify public values, (2) develop options, (3) estimate consequences, (4) weigh on alternative options, and (5) the decision itself. Public input can play important roles in the the first four stages. Figure 1 provides an overview of the public decision-making process and the expected output of each stage. Let us take a look at each stage in detail.

1. Identify public values. Public value refers to the desirable social outcomes that the political decision on a public issue should attain (e.g. enhancing public safety, improving public transportation), as well as the damages the decision should avoid (e.g. violating privacy, depreciating properties) [7, 17]. They provide a "legitimate social vision" on the goals that public believes that a decision should achieve [47]. However, public values cannot be reached by aggregating "what you and I individually care" [30]. Although many researchers acknowledge the necessity and the role of public values in the decision-making process, few have elaborated on the process and prerequisites of developing them. Our method (Section 5) will include an approach to filling this gap.

2. Develop options. A public issue can usually be addressed by many strategies. It is important that the public work together to explore all the possible alternative courses of action. The general public can contribute to expanding the solution space by brainstorming options and supplementing the public administrators' options.

3. Estimate the consequences of each option. After eliminating those options that are obviously not viable (ineffective, impractical, etc.), the next step is to estimate the consequences of each option in terms of the impact it has on each public value. The expected outcome of this stage is a performance profile for each option, featuring scientifically defensible judgments and verbal justifications on "how well a policy option addresses the public value" [40]. This process is both analytic and deliberative [33], in which technical and policy experts provide well-formed claims and scientific evidence, while citizens' personal knowledge and experiences are also of great importance in evaluating the options. Citizens may have a different perspective on how the proposed option impact a public value, pinpoint the side effects of an option, and give conclusions that are different from the experts.

4. Weigh on alternative options and generate preferences. This stage enables the general public to develop and express their attitude and relative preference in the options. The first goal of this stage is to compare alternative options and identify the trade-offs, in terms of the public values they attain or damage. Then, such information is made available to the public to enable them to generate their preferences and express their position. This process can also be deliberative [5, 28], in which individuals have the opportunity to be informed by each other on their choices and rationales. 
5. Make a decision. The output of the previous stage is fed back to the decision makers or authorities who finally make a decision and act.

\begin{tabular}{|c|c|}
\hline $\begin{array}{l}\text { 1. Identify public } \\
\text { values }\end{array}$ & Output: public values \\
\hline 2. Develop options & Output: a list of viable options \\
\hline $\begin{array}{l}\text { 3. Estimate the } \\
\text { consequences of each } \\
\text { option }\end{array}$ & $\begin{array}{l}\text { Output: judgments on the performance and } \\
\text { impact of all viable options (decision analysis) }\end{array}$ \\
\hline $\begin{array}{c}\text { 4. Weigh on alternative } \\
\text { options and generate } \\
\text { preferences }\end{array}$ & $\begin{array}{l}\text { Output: a distribution of general public's } \\
\text { preference over the options }\end{array}$ \\
\hline 5. Make a decision & \\
\hline
\end{tabular}

Figure 1: Public decision-making process.

This conception of collective decision-making process clearly shows that the quality of output from early stages has a significant impact on the later stages. In particular, having a consensus on the public values is crucial for evaluation of decision options. The quality of decision analysis in Stages 2 and 3 are the common basis for public opinions elicited in Stage 4 to be well-informed. There have been efforts (such as American Talk Issues Surveys and citizen study group [38, 20]) that solely focus on establishing consensus on intended social outcomes, expanding the range of solution options, and ensuring that balanced information is provided to the public. However, these efforts were not able to do the justice, even though they were designed with good intention [39]. When it comes to the need to organize collective decision making in communities, there is no prescription of public opinion elicitation methods that couple closely with the democratic decision-making process.

\subsection{Challenges Toward Collective opinions}

Based on critics of existing mass opinion methods and our field work with local State College borough government, we have identified three major challenges that need to be addressed when applying public opinion methods to local contexts:

Challenge I: How to identify public values? There is a lack of explicit process for recognizing and defining public values. Consequently, evaluation of potential solutions are not guaranteed to be against a set of values that represent the public interests. When opinions are expressed based on undeclared interests, collectivity of these judgments is compromised.

Challenge II: How to enable opinions to be formed on a solid information base and thorough analysis? There is no formal process for community members to participate in framing the issue and analyzing alternative solutions to address the issue.

Challenge III: How to foster collective opinion? Existing methods that involve small group deliberations for opinion formation offer possibilities for collective opinions to emerge from individual opinion expressions and communication. However, such process is not likely to happen naturally without explicit facilitation. In order for deliberative opinion elicitation methods to scale to massive online participation of large communities, explicit model of how individual opinions are molded into more collective form of opinions is needed.

\section{APPROACH TO PUBLIC OPINION FOR- MATION IN LOCAL COMMUNITIES}

Based on the analysis from the previous section, we believe that local governments should involve the public in all stages of a public decision-making process, and closely match the public opinion development process to the decision-making process. Our approach toward a comprehensive solution to the above challenges is to concatenate three deliberative public engagement sessions as a package. The first session is responsible for establishing public values for a given community and issue. The second session is responsible for conducting a full analysis of solution space and the pros-andcons of each alternative solution. The third session supports mass public opinion formation with the information generated from the first two sessions.

\subsection{Establishing public values}

The challenge in identifying public values in the first stage of public decision making lies in the seeking of the desirable social outcomes and the representation of the whole community's interest, which the community is committed to protect. The input of this process must include an enumeration of possible interests and social values in a comprehensive and systematic manner. In our approach, we address this challenge by inviting individuals from multiple stakeholder groups to the deliberation on public value identification, who are encouraged to contribute ideas from the standpoint of their stakeholder group. In the beginning of the deliberation, participants engage in a brainstorming of both social values (expectation on social groups) as well as private ones (what community members value).

Public values do not always align with individual interests. In the development of public values, "each of the citizens has to subordinate some of their individual ideas of what they want from the government to what the collective public wants from it" [30, p. 59]. Therefore, the second step of the deliberation is a converging process, in which the identified values are subject to elimination, aggregation and prioritization.

The final output of this process is a prioritized subset of initial values held in the community, which the whole community is committed to attain or enrich. The deliberation group is expected to reach certain degree of agreement on the public values.

\subsection{Developing decision analysis knowledge}

The development of decision analysis knowledge requires an intake of relevant information from a broad range of sources to the deliberation group for scrutiny. For public decision making in local governments, such knowledge typically involves two sources. The first source is elite discourse, including "politicians, higher-level government officials, journalists, some activists, and many kinds of experts 
and policy specialists" $[57$, p. 6$]$. The second source is the community members themselves, who contribute their personal and emotional experiences [5]. The development of a well-formed decision-analysis knowledge base requires that the deliberation group pay close attention to information from all these sources when forming a judgment.

The decision analysis knowledge serves as the input for the general public to take their position. Therefore, this knowledge must be presented in a clear, succinct, and comprehensive manner.

However, several barriers make this task difficult. First, it has long been noted that information usually exists in a very scattered manner, both spatially and temporally. Lippmann noted that public opinions "cover a bigger space, a longer reach of time, a greater number of things, than we can directly observe. They have, therefore, to be pieced together out of what others have reported and what we can imagine" [26, p. 79]. This claim entails that the development of decision analysis knowledge usually undertakes a dynamic process in which information snippets and clues are gradually gathered, and the key feature of this process is communication and learning. Second, given the large amount of information, the deliberation on the assessment and refinement of information imposes great challenges on the participants' cognitive capability.

The need for constructing a well-formed decision analysis knowledge base leads us to the following design rationales in our implementation:

1. The deliberation group is granted a structured access to information: policy experts and authorities are asked to present their knowledge on the issue as well as their position and argument. During the deliberation process, participants also have the opportunity to raise questions to the experts and authorities to seek further information.

2. The deliberation group is granted the opportunity to contribute their own knowledge and information gathered from other sources to the deliberation group for scrutiny.

3. The processes of understanding the source information and constructing consumable and informative decision analysis knowledge is carefully facilitated. Specifically, the process is divided into multiple steps to reduce people's cognitive load, and the informativeness, relevance and succinctness are closely attended during the deliberation process.

\subsection{Fostering collectivity}

Ideally, collectivity of an opinion requires that the community members believe that public opinion voices the need and judgments of the whole community in a legitimate way, even though such judgments may conflict with one's own interests. The key in this concept is a "shared mind" analogy: the opinions are unanimously endorsed by the community, as if the community possessed a single mind.

The way we interpret collectivity and the "shared mind" notion follows the large body of research in the collective intelligence area (e.g. $[15,53,25])$. We conceptualize the "sharedness" of public opinion as a mutual belief among the public on a certain opinion. This mutual belief protocol consists of the following clauses: first, each person individually has belief in the opinion. Second, each person beliefs that all others have belief in the opinion. On this common ground, the whole community could claim that "we have belief this opinion".

It should be noted that in this ideal case, having belief in an opinion does not mean agreement. Instead, the statement "I have belief in opinion $O$ " entails that "I believe that $O$ addresses at least one public value" and that "I believe that $o$ is justified by valid reasons".

The mutual belief requirement on public opinion imposes significant challenges on facilitation strategies in public deliberation. We develop the following rationales for the design of the public opinion formation protocol, human facilitation as well as online system design to foster the construction of mutual belief:

1. The identified public values and decision-making knowledge must be presented to the deliberation participants and at their disposal.

2. At any time of deliberation, opinions must be clearly presented and visualized, and all participants of deliberation must be encouraged to learn and reflect on each other's opinion, and express their attitude.

3. The online system should be able to present the degree of collectivity developed on each opinion.

\section{THE COMMUNITY OPINION ELICITA- TION (COPE): FOSTERING PUBLIC OPIN- ION FOR THE LOCAL}

Here we propose a solution package tailored to the need of local governments in fostering collective public opinion. In the United States, there are thousands of municipalities and townships that make up what are considered local governments. Other than providing basic services, many of these local governments are now exploring fresh approaches to "placemaking" and the strengthening of neighborhood communities, city regions, cultural spaces, and other aspects of civil society [45]. Each community has its unique public sphere consisting of the web of beliefs, places, organizations, rules, knowledge, and other cultural resources held in common by people, government and public institutions. Citizengoverned communities provide a society with some sense of belonging, meaning, purpose and continuity, which enables people to thrive and to strive amid uncertainty.

Recent survey of local e-government advances showed that American local governments offer a broader range of information, services and interactions online through their websites. However, as information and services continued to prevail ("low-hanging fruit"), paradigm shift to citizen-centric government (such as E-democracy) is missing, despite many optimistic claims of success [32].

Next, we describe Community Opinion Elicitation (COPE) as our approach to address the challenges of public opinion formation (Section 5.1). Implementation of this approach in real community engagement within State College Borough will be discussed in Section 5.2.

\subsection{The Structure of the COPE process}

The COPE process addresses the three challenges identified in Section 3 by concatenating three phases, each accomplishing one goal. Figure 2 provides an overview of the process. 


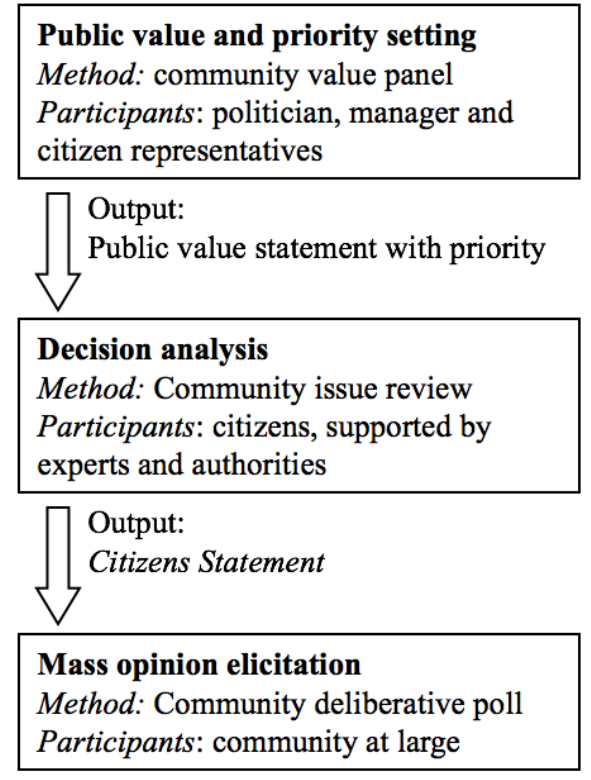

Figure 2: Three phases of the COPE process

\subsubsection{Phase I: Public value and priority setting}

The goal of this phase is to decide on the specific content of public value in relation to the pending public issue. We use a special panel of 10-24 people that represents balanced view points of politicians (members from city council), public managers (e.g. members from the planning department), and citizens (representatives from business and residents) to deliberate and develop a mutual belief on what the community values. The process can be roughly divided into three steps (following similar ideas in [36]):

Step 1: Value elicitation. The panel brainstorms on all the value dimensions that are held by individuals, subgroups, and organizations. The sources of information used by this panel include value statement of the city government $^{1}$, value statements of each service departments, strategic plans (where citizens values are reflected), as well as value statements contributed by the panel members and other individuals. Facilitation method is used to ensure the most inclusive set of value statements.

Step 2: Value analysis. The panel analyze all the value statements to eliminate those irrelevant to the current issue, aggregate similar ones, and identify a number of relatively orthogonal dimensions of values.

Step 3: Value choice and prioritization. The panel deliberate to form agreement in the choice of value dimensions that are considered truly important to be enriched and safeguarded. The panel is also asked to assign weights to the final value choices to reflect the priorities in case trade-offs have to be made due to limited resources or strategic options.

The following example demonstrates this process. Con-

\footnotetext{
${ }^{1}$ State College Borough has made the following explicit value statements through its website and strategic plan: to enhance the quality of life by fostering a safe, vibrant, diverse and sustainable community; Maintain stable and attractive neighborhoods; Expand housing opportunities; improve public spaces and community infrastructure; Foster commercial revitalization [48].
}

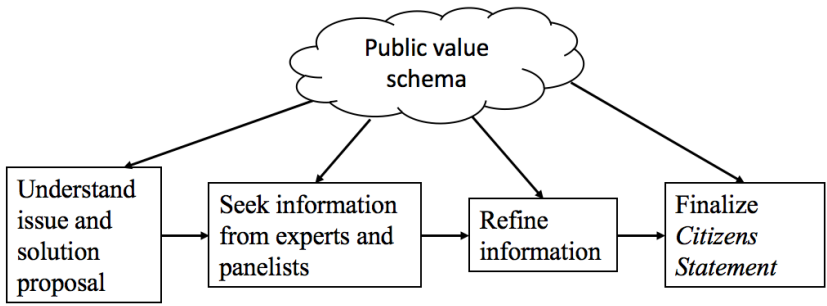

Figure 3: Community Issue Review (CIR) Process

sider a task of redesigning bus routes in the college town. The local community consists of students who commute to the campus daily, as well as downtown business owners. For students, different individuals care about different things (individual interests), such as ease of traveling, noise level, etc. The same is true for business owners. However, not all these interests must be covered by the decision on bus routing. Through deliberation they may come to an agreement that some of them are prioritized against others. In this way the community could collectively determine a subset of their initial interests, as well as developing new ones, that they are committed to protect.

The key to the value elicitation phase is the seeking of explicit agreement and endorsement on the values, so as to lay the basis for the following phases in COPE.

\subsubsection{Phase II: Community Issue Review (CIR)}

The Community Issue Review (CIR) process maps to the second and third stages of the public decision-making schema (see Section 3.1), with a goal of collecting, refining and consolidating decision relevant knowledge. Similar to Phase I, consensus and mutual belief is also sought in the conclusions of this phase. In practice, CIR works in a similar way to citizen juries [31], except with an output of a solid understanding on a policy issue, rather than producing a recommendation to decision body.

The CIR process involves a citizen panel of 12-24 people randomly selected from the community and lasts between four to seven days, depending upon the complexity of the issue and its proposed policy options. Typically, one or two moderators will assist the citizen panel in exploring and examining the issue from all dimensions. The panelists will work in plenary sessions, small groups as well as individually to ensure that everyone has the opportunity to contribute fully to the process.

The CIR process consists the following steps. First, the panelists are fully briefed on the issue and the proposed solution; they learn arguments and information provided by experts and witnesses. Then, they discuss the issue fully with the experts as well as among themselves. In this process they have the opportunity to ask for further information and to call their own witnesses. At the end of CIR, panelists draw together their conclusions and findings on the core matters about the issue and pros-and-cons on alternative policy options. The panel proceedings are compiled in a report in the form of a Citizens Statement which is made available online for public access, and serves as the decision analysis knowledge base for community-wide online deliberation.

\subsubsection{Phase III: Community Deliberative Poll}

True public opinion has to be inclusive. Participation 
needs to be large scale and representative of the whole population. We achieve this by incorporating a phase of massive deliberation through an online deliberation environment. In this phase, community members have access to the Citizens Statement developed in Phase II, which provides quality information about the issue, the proposed solutions, their objectives and expected effectiveness. With such information it is much more likely for community members to form their own opinion and take a position with ease and confidence. This serves as the basis for further deliberation where citizens engage in collective claim-making activities that gradually develops individual attitudes into collective public opinion [51].

Unlike traditional deliberative poll practice where inclusiveness is achieved by random selection into small-group deliberation, our method in Community Deliberative Poll takes advantage of information and communication technologies and allows the community at large to deliberate together through a moderated online forum. For each issue to be reviewed, an online deliberative forum is created that presents the Citizens Statement and hosts further moderated deliberative discussions among the general public.

This three-phase design of the COPE process matches the first three phases of the public decision-making schema specified in Section 3.1. Particularly, by developing dedicated value identification and decision analysis processes (Phases I and II) before the mass deliberation (Phase III), the COPE method significantly reduced the information barrier.

\subsection{Implementing COPE process for local gov- ernment}

In collaboration with our local government partner, State College Borough, $\mathrm{PA}^{2}$, we have implemented COPE method as a practical solution for constructing public opinion in making local policy decisions. The Borough is structured in the well-known "council-manager" form, where the city is run by a city manager under the direction of the city council. The city council is the political entity that sets policy and has ultimate responsibility for the municipal government. Members of Council work on a part-time basis without compensation. Council appoints a Borough Manager to serve as the chief executive officer of the Borough, who is responsible for overseeing all of the operating departments, such as planning, parking, police and public works.

Currently, State College Borough uses several venues (town meetings, neighborhood conversations, stakeholder workshops and online forums) for engaging the broader community when public opinion on a pending decision is needed. The city regularly announces upcoming council meetings and organizes small-group meetings to gauge public attitude toward the proposed project or ordinance. However, our interview with council members confirmed that participation is quite low and comments received are hardly representative of the whole community.

In this section, we describe our two pilot experiments of the COPE process with the State College Borough in the past two years, followed by an analysis of the special features of COPE implementation tailored to the need of State College Borough.

\subsubsection{Overview of the implementation}

\footnotetext{
$\overline{{ }^{2} \text { http://www.statecollegepa.us/ }}$
}

In the past two years, we have implemented the COPE method with the State College Borough on two proposals. The first proposal was implementing surveillance cameras in one of the Borough's neighborhoods to improve public safety. The second proposal was an ordinance intended to increase the value of the downtown and community by incentivizing developers to provide first floor commercial space, maintain pedestrian access, and increase residential space and building height.

The implementation of the COPE process in a local government such as State College Borough is faced with two challenges. First, for Phases I and II, although small group, face-to-face deliberation has the potential to achieve best democratic and deliberative qualities, due to the task complexity, these two phases are likely to cost participants $5-7$ days of dedicated effort. This presents significant barriers to recruiting representative members from the public. To overcome this difficulty, we carefully engineered the activities in these two phases as a combination of online and face-to-face deliberation. This strategy is discussed in further detail in Section 5.2.2.

Second, an combination of online and face-to-face deliberation requires an adaptation of traditional facilitation strategies. In our implementation, human facilitation is performed for both the face-to-face sessions as well as for online sessions.

\subsubsection{Combining online and face-to-face delibera- tion}

In our field practice in State College Borough, Phase $I$ is run as a two-week process, but the whole panel meet face-toface only twice - a 2-hour meeting on the first day, and another 2-hour meeting at the end to finalize community value statements. During the time in between, the panel deliberate online and the facilitator uses both synchronous (chats) and asynchronous communication (messages and posts).

Similarly, Phase II (Community Issue Review) is also run as a two-week process. The whole panel meets face-to-face only on the first day and on the last day for two hours each. Most of the CIR process are done through an online deliberative forum where panel members and the facilitator collaborate remotely.

Online deliberation is performed on our prototype system, GeoDeliberator. First, the panel develop their understanding on the issue through reading expert-written documents, extracting knowledge nuggets, and interacting directly with experts using the $\mathrm{Q} \& \mathrm{~A}$ function. This process is the online implementation of the information-seeking process described in Section 5.1.2. Figure 4 demonstrates the user interface of this process.

Then, CIR panelists consolidate and improve the opinions and findings they composed (Figure 5), and finalize Citizens Statement. After the CIR process ends, the system presents the Citizens Statement with links that reveal the process each opinion is generated, as well as a discussion board for Phase III community-wide deliberation (Figure 6).

Feedback from the panel members considered this as a huge innovation because of the significant reduction of time and effort by participating online. They like the flexibility of deliberation online without interrupting their regular work and family life. 


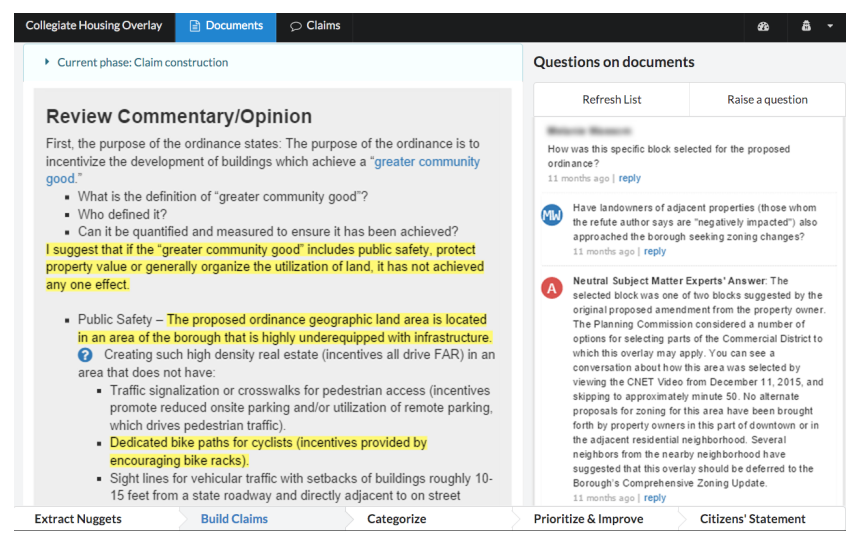

Figure 4: Information base construction from expert-written document annotation and online $Q$ \& A.

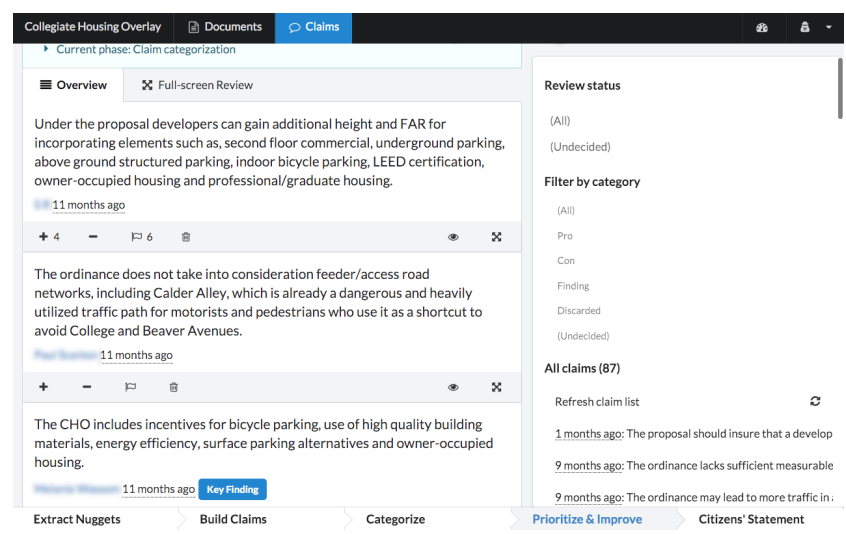

Figure 5: Citizen panel consolidate claims and findings and prepare Citizens Statement.

\subsubsection{Structuring deliberation through human facil- itation}

In our implementation, all three phases of COPE are facilitated by a professional moderator to ensure democratic and deliberative quality of the conversation.

For each issue considered, an online deliberative forum is created on our GeoDeliberator portal ${ }^{3}$. The facilitator is provided with a control panel for evaluating the status of participation of different panelists, coordinating the citizen panel and subject matter experts in information exchange, and directing the panel to move through steps and phases of the COPE process, and for monitoring the status of deliberation. Full description of the facilitation strategy is beyond the scope of this paper, but the tasks of the facilitation is complex enough to overwhelm even professional facilitators. We designed visual-cognitive aids in the online forum to enable facilitators monitoring the situation and making choices from a variety of facilitation strategies.

The face-to-face meeting on the last day of the CIR process was aimed at finalizing the Citizens Statement. Figure 7 shows a facilitator guiding a panel of participants in refining and prioritizing their findings from the online deliberation.

\footnotetext{
$\overline{{ }^{3} \text { http://geodeliberation.ist.psu.edu }}$
}

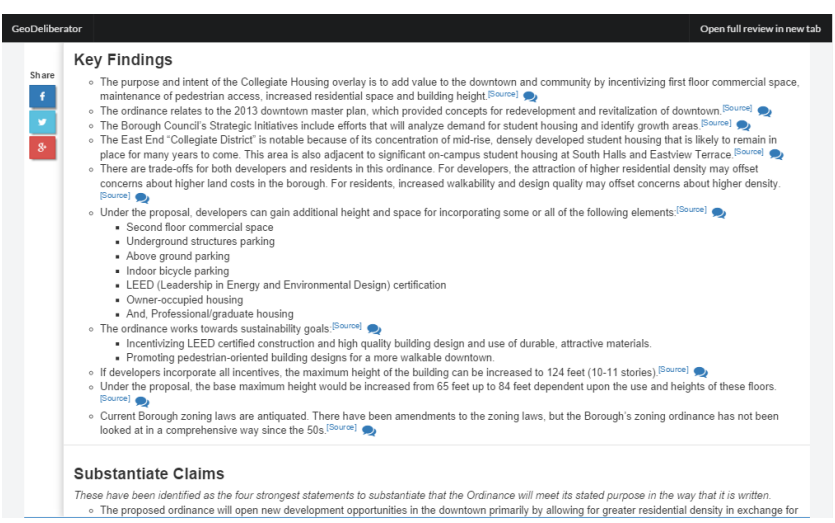

Figure 6: Citizens Statement on decision analysis knowledge.

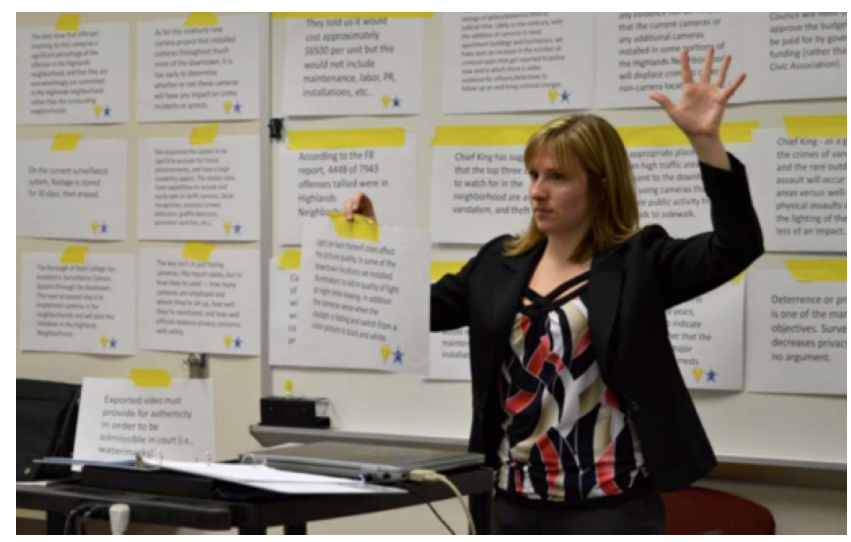

Figure 7: Facilitation in CIR deliberation

\section{DISCUSSION AND CONCLUSION}

Online deliberation technologies have been used to elicit public opinions on local issues and policy decisions, and most of the methods underlying these technologies are drawn from prior methods of small group deliberation. In both online and offline contexts, achieving collective and well-informed public opinion remains an open challenge. We have proposed a method to address the need of constructing collective public opinion in local public decision making. Our method addresses three weaknesses of current online deliberation technologies as tools for collecting public opinion: (1) the lack of a shared recognition on public values; (2) the lack of solid decision information and analysis; and (3) the lack of explicit measure of collectivity in the process of opinion formation. Our contribution is to structure public opinion collection into a three-phase process, with the first two phases dedicated to building common grounds in public values and decision information.

Two field experiments of this method have been completed in collaboration with the State College Borough government, and the results will be reported in separate venues. Feedback from our local government partner has been positive so far [21]. Specifically, public values are identified through small group deliberation in the first stage, which guided all subsequent deliberative activities, including developing decision analysis knowledge and informing Phase III public deliberation. In the online session of the CIR process, a pre- 
liminary analysis of the panel's online activities reveals that the participants were actively engaged in making sense of the experts' articles, collaboratively identifying and refining relevant information, and actively expressing their attitude on the information products. At the end of the CIR process, each panelist was confident on the agreement and quality of the Citizens Statement. The impact of this phase has been publicized $^{4}$. In the Phase III mass deliberation, our preliminary survey reveals that the identified public values and the Citizens Statement were informative and effective in helping the general public form their political opinions with confidence.

Although the general direction of this research seems promising, the actual implementation and practice of the method in local government still faces many challenges and uncertainties. First, the way we identify and compose review panels for Phase I and Phase II has been questioned and we still do not have a clear principle to guide such practice.

Second, the design of our online deliberation tool is less sophisticated and not tailored to the task of fostering public opinion formation. If the system is "aware of" the status of public opinion at a given moment and could infer the directions in which public opinion can be more collective, then algorithms could be developed to prompt participants with further actions and partially undertake facilitation task. This requires a systematic and theoretical understanding of the process of public opinion formation in public deliberation.

If we are successful in addressing these questions, our method is likely to make a real impact on transforming local government by an open and participatory public sphere.

\section{ACKNOWLEDGMENTS}

We would like to acknowledge funding support from National Science Foundation under award \# IIS-1211059.

\section{REFERENCES}

[1] E. L. Bernays. Crystallizing Public Opinion. Liveright Publishing Corporation, New York, 1923.

[2] H. Blumer. Public opinion and public opinion polling. American Sociological Review, 13(5):542-549, 1948.

[3] D. Bollier. The Rise Of Collective Intelligence: Decentralized Co-Creation of Value as a New Paradigm of Commerce and Culture. Technical report, Aspen Institute, 2007.

[4] T. Bosse, C. M. Jonker, M. C. Schut, and J. Treur. Collective representational content for shared extended mind. Cognitive Systems Research, 7:151-174, 2006.

[5] S. Burkhalter, J. Gastil, and T. Kelshaw. A Conceptual Definition and Theoretical Model of Public Deliberation in Small Face-to-Face Groups. Communication Theory, 12(4):398-422, 2002.

[6] J. N. Cappella, V. Price, and L. Nir. Argument Repertoire as a Reliable and Valid Measure of Opinion Quality: Electronic Dialogue During Campaign 2000. Political Communication, 19:73-93, 2002.

[7] S. Chambers. Deliberative Democratic Theory. Annual Review of Political Science, 6:307-326, 2003.

\footnotetext{
${ }^{4}$ http://crossroads.newsworks.org/index.php/local/ keystone-crossroads/76168
}

[8] P. E. Converse. Changing Conceptions of Public Opinion in the Political Process. The Public Opinion Quarterly, 51(2):S12-S14, 1987.

[9] T. Davies and S. P. Gangadharan. Online Deliberation: Design, Research and Practice. CSLI Publications, 2009.

[10] J. S. Fishkin. Democracy and deliberation: New directions for democratic reform. Yale University Press, New Haven, CT, 1991.

[11] J. S. Fishkin, R. C. Luskin, and R. Jowell. Deliberative Polling and Public Consultation. Parliamentary Affairs, 53:657-666, 2000.

[12] P. Garrido. Business sustainability and collective intelligence. The Learning Organization, 16(3):208-222, 2009.

[13] J. Gastil. A Definition of Small Group Democracy. Small Group Research, 23(3):278-301, 1992.

[14] S. G. Grimmelikhuijsen. Transparency of Public Decision-Making: Towards Trust in Local Government? Policy \& Internet, 2(1):4-34, 2010.

[15] B. J. Grosz and S. Kraus. Collaborative plans for complex group action. Artificial Intelligence, 86(95):269-357, 1996.

[16] T. Gruber. Collective knowledge systems: Where the Social Web meets the Semantic Web. Web Semantics: Science, Services and Agents on the World Wide Web, 6(1):4-13, 2008.

[17] A. Gutmann and D. Thompson. Why Deliberative Democracy. Princeton University Press, 2009.

[18] J. Habermas. The Structural Transformation of the Public Sphere: An Inquiry into a Category of Bourgeois Society (T. Burger Trans.). MIT Press, Cambridge, MA, 1989.

[19] D. Janssen and R. Kies. Online Forums and Deliberative Democracy. Acta Politica, 40(3):317-335, 2005.

[20] A. F. Kay, H. Henderson, F. Steeper, and C. Lake. Interviews with the Public Guide us ... On the Road to Consensus. Americans Talk Issues Foundation, St. Augustine, Florida, 1994.

[21] J. Kropczynski, G. Cai, and J. M. Carroll. Understanding the Roles of Artifacts in Democratic Deliberation from the Citizens' Initiative Review. Journal of Social Media for Organizations, 2(1), 2015.

[22] J. H. Kuklinski and P. J. Quirk. Reconsidering the rational public: Cognition, heuristics, and mass opinion. In A. Lupia and M. D. McCubbins, editors, Elements of Reason: Cognition, Choice and the Bounds of Rationality, pages 153-182. 2000.

[23] H. Landemore and J. Elster. Collective Wisdom: Principles and Mechanisms. Cambridge University Press, New York, 2012.

[24] A. C. Leoveanu. Rationalist model in public decision making. Journal of Public Administration, Finance and Law, (4):43-54, 2013.

[25] H. J. Levesque, P. R. Cohen, and J. H. T. Nunes. On Acting Together. Proceedings of the Eighth National Conference on Artificial Intelligence, 61:94-99, 1990.

[26] W. Lippmann. Public Opinion. Harcourt Brace Jovanovich, New York, 1922.

[27] B. Manin. On Legitimacy and Political Deliberation. 
Political Theory, 15(3):338-368, 1987.

[28] D. Mathews. Politics for people: Finding a responsible public voice. University of Illinois Press, Chicago, 1994.

[29] M. L. McCoy and P. L. Scully. Deliberative Dialogue to Expand Civic Engagement: What Kind of Talk Does Democracy Need? National Civic Review, 91(2):117-135, 2002.

[30] M. H. Moore. Recognizing Public Value. Harvard University Press, Cambridge, MA, 2013.

[31] G. Munno and T. Nabatchi. Public Deliberation and Co-Production in the Political and Electoral Arena: A Citizens' Jury Approach. Journal of Public Deliberation, 10(2), 2014.

[32] D. F. Norris and C. G. Reddick. Local E-Government in the United States: Transformation or Incremental Change? Public Administration Review, 73(1):165-175, 2013.

[33] T. Nyerges and R. W. Aguirre. Public Participation in Analytic-Deliberative Decision Making: Evaluating a Large-Group Online Field Experiment. Annals of the Association of American Geographers, 101(3):561-586, 2011.

[34] B. I. Page and R. Y. Shapiro. Effects of Public Opinion on Policy. The American Political Science Review, 77(1):175-190, 1983.

[35] B. I. Page and R. Y. Shapiro. The Rational Public: Fifty Years of Trends in American's Policy Preferences. University of Chicago Press, Chicago, 1992.

[36] S. J. Peacock. Public attitudes and values in priority setting. Israel journal of health policy research, 4:29, 2015.

[37] V. Price. The Public and Public Opinion in Political Theories. In W. Donsbach and M. W. Traugott, editors, The SAGE Handbook of Public Opinion Research, pages 7-24. SAGE Publication, London, 2008.

[38] V. Price and P. Neijens. Opinion Quality in Public Opinion Research. International Journal of Public Opinion Research, 9(4):336-360, 1997.

[39] V. Price and P. Neijens. Deliberative polls: Toward improved measures of "Informed" public opinion? International Journal of Public Opinion Research, 10(2):145-176, 1998.

[40] O. Renn, T. Webler, H. Rakel, P. Dienel, and B. Johnson. Public participation in decision making: A three-step procedure. Policy Sciences, 26:189-214, 1993.

[41] D. Rios Insua, G. E. Kersten, J. Rios, and C. Grima. Towards decision support for participatory democracy. Information Systems and e-Business Management, 6(2):161-191, 2008.

[42] N. Roberts. Public Deliberation in an Age of Direct Citizen Participation. The American Review of Public Administration, 34(4):315-353, 2004.

[43] G. Rowe and L. J. Frewer. Public Participation Methods: A Framework for Evaluation. Science, Technology \& Human Values, 25(1):3-29, 2000.

[44] G. Rowe and L. J. Frewer. A Typology of Public Engagement Mechanisms. Science, Technology 86 Human Values, 30(2):251-290, 2005.
[45] M. R. Rutgers. As Good as It Gets? On the Meaning of Public Value in the Study of Policy and Management. American Review of Public Administration, 45(1):29-45, 2015.

[46] D. M. Ryfe. The Practice of Deliberative Democracy: A Study of 16 Deliberative Organizations. Political Communication, 19:359-377, 2002.

[47] D. M. Ryfe. Toward a Sociology of Deliberation. Journal of Public Deliberation, 3(1):1-27, 2007.

[48] State College Borough. The Borough of State College Strategic Plan. Technical report, 2009.

[49] J. Stromer-Galley. Measuring Deliberation's Content: A Coding Scheme. Journal of Public Deliberation, 3(1), 2007.

[50] J. Surowiecki. The wisdom of crowds: why the many are smarter than the few and how collective wisdom shapes business, economies, societies, and nations. Doubleday, New York, 2004.

[51] Y. Tian and G. Cai. Modeling Claim-making Process in Democratic Deliberation. In E. Yu, G. Dobbie, M. Jarke, and S. Purao, editors, Conceptual Modeling, pages 458-465. Springer, 2014.

[52] W. B. Towne and J. D. Herbsleb. Design Considerations for Online Deliberation Systems. Journal of Information Technology 8 Politics, 9(1):97-115, 2012.

[53] R. Tuomela. Collective and joint intention. Mind 8 Society, 1:39-69, 2000.

[54] R. van der Merwe and A. Meehan. Direct Deliberative Governance Online: Consensual Problem Solving or Accommodated Pluralism? Journal of Information Technology \& Politics, 9(1):46-63, 2012.

[55] D. Yankelovich. Coming to public judgment: Making democracy work in a complex world. Syracuse University Press, New york, 1991.

[56] W. Yuan, Y. Chen, R. Wang, and Z. Du. Collective Intelligence in Knowledge Management. International Federation for Information Processing, 254:651-655, 2007.

[57] J. Zaller. The Nature and Origins of Mass Opinion. Cambridge University Press, Cambridge, 1992. 